\title{
LOS HOMICIDIOS CULPOSOS EN COSTA RICA: ANÁLISIS DEL PERIODO 2000-2009
}

\section{MANSLAUGHTERS IN COSTA RICA: ANALYSIS 2000-2009}

\author{
Mario Alberto Sáenz Rojas*
}

RESUMEN

Este artículo $^{1}$ presenta las cifras absolutas y relativas referentes a los homicidios culposos o imprudentes ocurridos en Costa Rica, durante el periodo 2000-2009, donde se aprecia un leve descenso en la tasa por cien mil habitantes; asimismo, se establece una comparación entre la tasa de estos homicidios y las correspondientes a otras formas de muerte violenta en el país. Además, se analizan algunas variables sociodemográficas de las víctimas, destacándose la abrumadora mayoría de hombres, personas jóvenes y costarricenses.

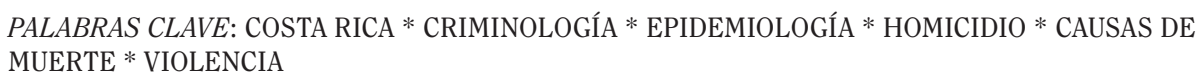

\section{ABSTRACT}

This article shows the relative and absolute numbers in relation to manslaughters or homicides by negligence occurred in Costa Rica, during the period 2000 to 2009. The numbers show a slight reduction in the rate for every a hundred thousand habitants, and establish a comparison between the homicide rate and other forms of violent death in the country. Furthermore, some socio-demographic variables of the victims are analyzed, most of them men, youngers and Costa Ricans.

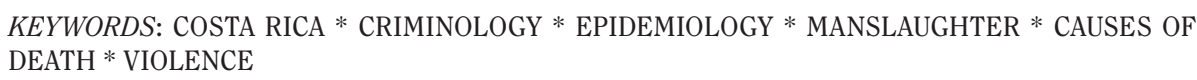
* Escuela de Psicología de la Universidad Católica de Costa Rica y Oficina de Atención a la Víctima del Poder Judicial de Costa Rica.
msaenzr@poder-judicial.go.cr/masaenz65@gmail.com

$1 \quad$ El autor desea dejar constancia de su gratitud a la Fiscal Adjunta M. Sc. Paula Guido Howell, quien a partir de su experiencia, realizó varias observaciones de mucho provecho para mejorar la calidad del documento. 


\section{INTRODUCCIÓN}

No cabe duda que la vida humana es el bien jurídico tutelado por excelencia en el derecho penal occidental $y$ es consagrada en los principales instrumentos jurídicos en materia de derechos humanos.

Por otra parte, se ha establecido que en el campo de las muertes violentas, los homicidios culposos obtienen la tasa más alta, en comparación con los homicidios dolosos y los suicidios (Sáenz, 2010).

El legislador costarricense ha contemplado el Homicidio Culposo en el artículo 117 del Código Penal, donde se establecen diversos tipos de penas dependiendo de la forma en que se haya producido el resultado de muerte.

Se impondrá prisión de seis (6) meses a ocho (8) años, a quien por culpa mate a otro. En la adecuación de la pena al responsable, el tribunal deberá tomar en cuenta el grado de culpa y el número de víctimas, así como la magnitud de los daños causados.

En todo caso, al autor del homicidio culposo también se le impondrá inhabilitación de uno (1) a cinco (5) años para el ejercicio de la profesión, el oficio, arte o la actividad en la que se produjo el hecho. Al conductor reincidente se le impondrá, además, la inhabilitación para conducir todo tipo de vehículos, por un periodo de cinco (5) a diez (10) años.

Se impondrá pena de prisión de tres (3) a quince (15) años e inhabilitación para la conducción de todo tipo de vehículos, por un periodo de cuatro (4) a veinte (20) años, a quien, por culpa $y$ por medio de un vehículo, haya dado muerte a una persona, encontrándose el autor bajo las condiciones establecidas para la conducción temeraria, conforme se dispone en los incisos b), c) y d) del numeral 107 de la Ley de tránsito por vías públicas terrestres, $\mathrm{N}^{\circ} 7331$, de 13 de abril de 1993, y sus reformas, o bajo la influencia de bebidas alcohólicas, cuando la concentración de alcohol en la sangre sea mayor a cero como setenta $y$ cinco $(0,75)$ gramos de alcohol por cada litro de sangre.

Cuando se trate de un conductor reincidente de alguna de las conductas señaladas en el párrafo anterior, el mínimo de la pena de inhabilitación para la conducción de todo tipo de vehículos, será de diez (10) años y el máximo podrá ser hasta de treinta (30) años. Cuando se imponga una pena de prisión de tres (3) años o menos, el tribunal podrá sustituir la pena privativa de libertad, por una medida alternativa de prestación de servicios de utilidad pública, que podrá ser de trescientas ochenta (380) horas a mil ochocientas (1800) horas de servicio, en los lugares $y$ la forma señalados en el artículo 71 ter de la Ley de tránsito por vías públicas terrestres, $\mathrm{N}^{\circ} 7331$, de 13 de abril de 1991, y sus reformas (Zúñiga, 2009: 77-78).

Para el caso argentino, Sproviero señala que:

La prolija enumeración de las posibilidades generadoras de culpa queda expresada en la imprudencia, negligencia o impericia a las que se hace mención en el artículo en debate consignando a posteriori que aquellas cuestiones culposas pueden responder "a la inobservancia de reglamentos o deberes a su cargo..." ${ }^{2}$ (1996: 146).

Un aspecto esencial de este tipo penal, lo aporta el Código Penal español, en el cual se denomina a este homicidio como "imprudente", según el mismo artículo 142 del código de 1995 (Ganzenmüller, Escudero y Frigola, 1996).

Para estos autores, el núcleo del tipo es la falta al deber de cuidado. Entre los tipos de

$\overline{2} \quad$ Se refiere al artículo 84 del Código Penal argentino. 
injusto de los delitos dolosos y los delitos culposos media el hecho de que en los primeros interviene el elemento subjetivo de conocimiento del tipo y el deseo de realización, mientras que en los segundos, únicamente debe concurrir la imprudencia, lo que constituye la infracción al deber objetivo de cuidado como elemento objetivo del tipo; en este sentido: “... en los tipos culposos las acciones se individualizan porque el resultado advierte en razón de una falta de cuidado en la programación final del agente" (Zaffaroni, Alagia y Slokar, 2003: 444).

El deber de cuidado (objetivo y normativo), no se puede encontrar en la norma legal. Es objetivo, por cuanto no interesa para establecer lo cuál es el cuidado que en el caso concreto ha aplicado o podría aplicar el autor, ya que esta es una cuestión que afecta a la culpabilidad, sino cuál es el cuidado requerido en la vida de relación social respecto a la realización. Ello supone un juicio normativo que surge de la comparación entre la conducta que hubiera seguido un hombre razonable $y$ prudente en la situación del autor y la observada por el autor realmente (Ganzenmüller, Escudero y Frigola, 1996: 73-74).

Además, aclaran Ganzenmüller et ál. (1996) que el solo hecho de poner en práctica la conducta imprudente, no constituye el delito de esa misma denominación, sino que debe existir entre la conducta peligrosa y el resultado (muerte) un vínculo de causalidad: "debe darse una conexión que le permita atribuir ya en el plano objetivo ese resultado concreto que se ha producido, al autor de la acción imprudente realizada" (p. 75).

En este sentido, cabe destacar que la previsibilidad objetiva del resultado debe ser entendida como parte del concepto de imprudencia, puesto que permite anticipar la posibilidad del resultado y con ello evitarlo (Ganzenmüller, Escudero y Frigola, 1996). De esta manera:

... el tipo culposo no castiga al autor por la forma en que un fin es perseguido, sino porque el resultado distinto al final presupone de parte del causante un peligro prohibido previsible $y$ evitable, $y$ ello se explica porque la mera creación de un peligro no es suficiente para la imputación culposa (Zaffaroni et ál., 2003: 549).

Así, deben concurrir cinco elementos para que se dé un homicidio culposo o imprudente: 1) la acción u omisión no debe ser dolosa; 2) la actuación negligente del agente por su falta de cuidado o previsión; 3) la infracción del deber objetivo de cuidado como factor normativo; 4) el homicidio culposo como un delito de resultado (muerte) previsible y evitable y 5) el nexo causal entre la falta del debido cuidado $y$ el daño producido.

\section{ANTECEDENTES}

En un primer orden, se destaca que es sabido que la principal fuente de homicidios culposos está asociada con los accidentes de tránsito (Carranza, 1994). En este contexto, las implicaciones de la ingestión problemática de bebidas alcohólicas y otras drogas cobran mayor atención cuando entra en juego el riesgo de muerte violenta. De hecho, de acuerdo a estadísticas internacionales, en el mundo se suscitan cada hora, 35 muertes asociadas con el consumo de etanol o alcohol etílico y los accidentes de tránsito (Matos, Betancourt, Álvarez, Aces y Toirac, 2001).

Por ejemplo, en un estudio realizado con los pacientes ingresados por accidente de tránsito e intento de homicidio en la sala de emergencias de dos hospitales generales de la ciudad de Santo Domingo, República Dominicana, se halló que el 78\% del total de casos, ingerían alcohol en el momento en que sucedió el hecho violento, de los cuales el 54\% refirió un consumo excesivo (Feliz, de la Cruz, de los Santos y Ramos, 1992).

Carranza (1994) estableció que los homicidios culposos son la mayor fuente de muertes violentas en Costa Rica, a pesar de lo cual se le da menos atención en los medios de difusión y por ende, cuentan con menor impacto emocional.

Entre 1983 y 1992, estos homicidios mostraron una clara tendencia al alza, pasando la tasa por cada cien mil habitantes de 6,5 a 
10,4 entre ambos extremos de dicho periodo, tendencia que es similar en el caso de las lesiones culposas (Carranza, 1994).

Asimismo, en un estudio realizado en Costa Rica, Moreno y Monge (2009) establecieron los siguientes aspectos de relevancia:

$\diamond \quad$ Las carreteras con poco tránsito es una variable que se correlaciona con la intención de incrementar la velocidad vehicular.

$\diamond \quad$ Las carreteras en rectas correlacionan más que aquellas en curva con la intención de aumentar la velocidad.

$\diamond \quad$ Cometer violaciones a las reglas de tránsito es un predictor de la intención de aumentar la velocidad.

$\diamond \quad$ A menor edad del conductor, mayor la intención de incrementar la velocidad.

$\diamond \quad$ Mantener un vínculo de pareja $y$ tener hijos/as se correlacionó también con la intención de aumento de velocidad.

$\diamond \quad$ A mayor estatura del conductor, mayor la intención de incrementar la velocidad.

$\diamond \quad$ Se dio una correlación significativa entre características de personalidad (búsqueda de experiencias, desinhibición y susceptibilidad al aburrimiento) con la cantidad de infracciones $y$ de accidentes.

Paralelamente, Moreno y Monge (2011) establecieron a partir del mismo estudio que:

$\diamond \quad$ A mayor inclinación por actitudes favorables hacia los comportamientos de riesgo en conductores costarricenses, menos actitudes favorables hacia comportamientos protectores.

$\diamond \quad$ A menor edad, más actitudes favorables hacia el riesgo y más comportamientos de riesgo al conducir.

$\diamond \quad$ La intención de aumento de velocidad en condiciones óptimas correlacionó con actitudes favorables hacia el riesgo $y$ comportamientos de riesgo.

\section{OBJETIVOS}

De esta manera, el presente trabajo se ha planteado los siguientes objetivos:
1. Establecer la magnitud y frecuencia de los homicidios culposos ocurridos en Costa Rica, durante el periodo 2000-2009.

2. Determinar las principales características sociodemográficas de las víctimas en los casos de homicidios culposos ocurridos en Costa Rica, durante el periodo 2000-2009.

3. Describir algunas características psicosociales, tales como contexto de género, modalidad y contexto espacio-temporal que rodearon los homicidios culposos ocurridos durante el periodo 2000-2009.

\section{ASPECTOS METODOLÓGICOS}

Para efectos de la recolección de los datos, se tomaron los anuarios de estadísticas policiales del Poder Judicial que se encuentran disponibles en su página web. En cuanto al análisis, el hecho de contar con las bases de datos, pero únicamente con los informes estadísticos publicados, impidió realizar análisis estadísticos de mayor profundidad que permitieran establecer medidas de tendencia central y grados de relación entre diferentes variables y sus niveles de significancia.

Lamentablemente se contó con la limitación de que los anuarios de estadísticas policiales no registran la información sociodemográfica del presunto responsable del homicidio $y$ en el caso de la víctima, se reduce las variables de sexo, edad y país de origen, así como tampoco se detalla la presencia de alcohol en sangre en ninguno de estos sujetos partícipes (sujeto activo y pasivo del hecho punible).

\section{MAGNITUD Y FRECUENCIA}

En la tabla 1, se muestra la cantidad de víctimas por homicidio culposo y la tasa por cien mil habitantes para el periodo 2000-2009. De esta manera, el número absoluto de personas fallecidas evidencia una variación constante, con aumentos y descensos reiterados, lo cual podría asociarse con las diversas reformas a la Ley de Tránsito que ocurrieron en dicho periodo, alcanzando un total de 5895 personas fallecidas, para un promedio anual de 589,5 muertes por homicidio culposo. 
TABLA 1

PERSONAS FALLECIDAS EN COSTA RICA POR HOMICIDIO CULPOSO

2000-2009

(VALORES ABSOLUTOS Y RELATIVOS)

\begin{tabular}{|c|c|c|c|}
\hline AÑO & NRO DE VÍCTIMAS & $\begin{array}{c}\text { POBLACIÓN TOTAL AL } 1^{\circ} \text { DE JUNIO } \\
\text { DE CADA AÑO }\end{array}$ & TASA POR 100 MIL HABITANTES \\
\hline 2000 & 602 & 3925331 & 15,3 \\
\hline 2001 & 623 & 4008265 & 15,5 \\
\hline 2002 & 578 & 4089609 & 14,3 \\
\hline 2003 & 528 & 4169730 & 12,7 \\
\hline 2004 & 558 & 4248481 & 13,1 \\
\hline 2005 & 552 & 4215569 & 13,1 \\
\hline 2006 & 601 & 4269884 & 14,1 \\
\hline 2007 & 617 & 4325540 & 14,3 \\
\hline 2008 & 643 & 4381987 & 14,7 \\
\hline 2009 & 593 & 4438995 & 13,4 \\
\hline
\end{tabular}

Fuente: Anuarios de Estadísticas Policiales del Poder Judicial, 2000-2009.

Asimismo, la tasa anual presenta un comportamiento variable, mostrando descensos y aumentos periódicos durante la década, para una tasa promedio anual de 14 personas fallecidas por homicidio culposo por cada 100000 habitantes. Aunque las cifras no muestran una constante tendencia al alza, es destacable que este tipo de muerte violenta constituye una gran preocupación desde la perspectiva de la salud pública, la violencia social y los derechos humanos, puesto que evidencia que la vida humana se pone en riesgo por niveles elevados de falta al deber de cuidado (entiéndase imprudencia, negligencia o impericia, términos que la jurisprudencia nacional ha dejado de utilizar), denotando un desprecio por los resultados de sus acciones, al punto de constituir la forma de muerte violenta que registra la proporción más alta en el país.

En la figura 1 se aprecia la tasa de víctimas de homicidio culposo por cada 100000 habitantes a lo largo de 20 años (1990-2009). Esta gráfica confirma la tendencia irregular aunque ligeramente ascendente de la misma, pasando de 10,2 en 1990 a 13,4 en 2009 , lo que implica un alza de 3 víctimas de homicidio culposo por cada 100000 habitantes en dicho lapso, alrededor de un aumento del $33 \%$. 
FIGURA 1

TASA DE VÍCTIMAS DE HOMICIDIO CULPOSO POR 100000 HABITANTES

COSTA RICA, 1990-2009

(VALORES ABSOLUTOS)

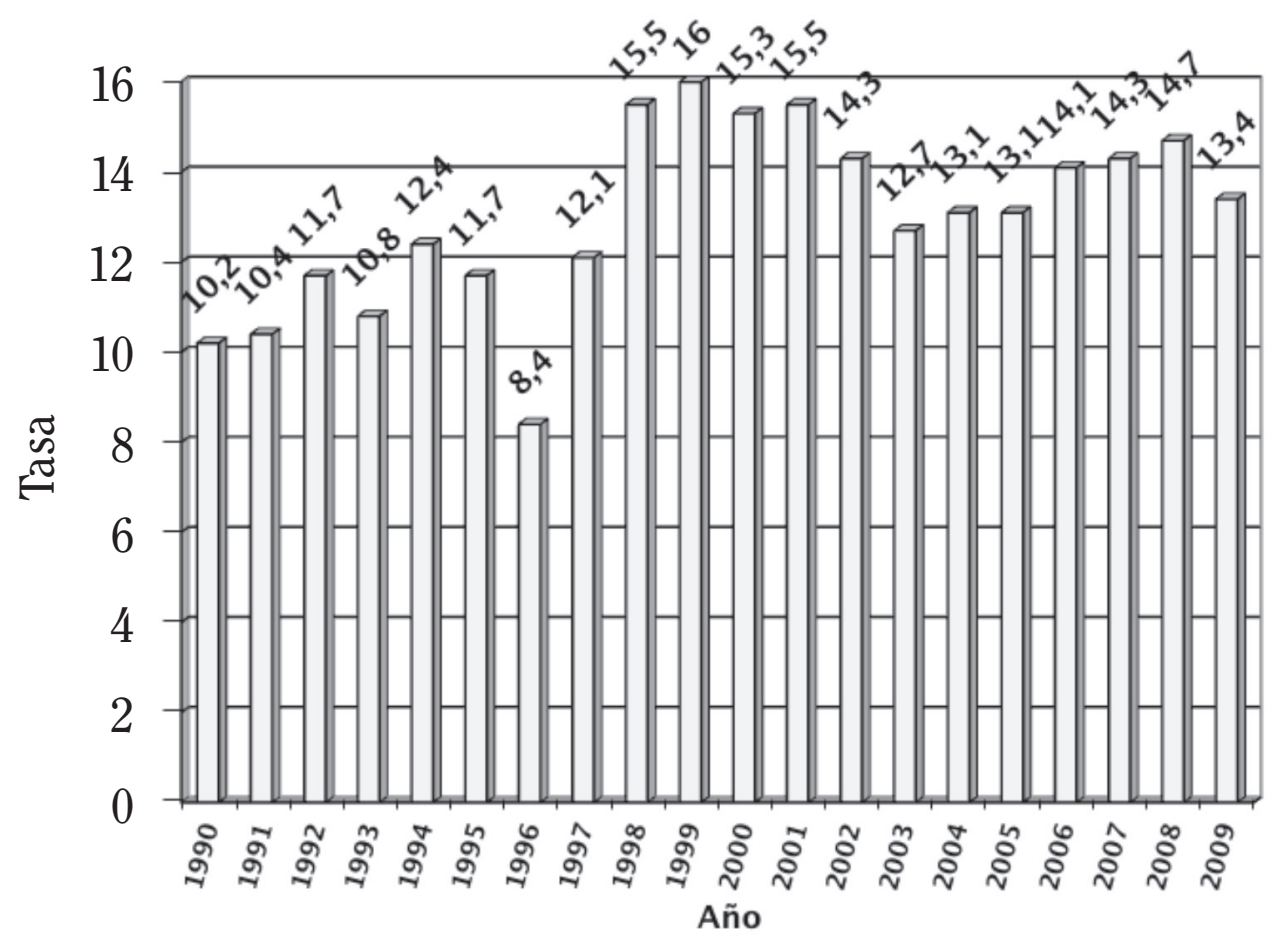

Fuente: Anuarios de Estadísticas Policiales del Poder Judicial, 1990-2009.

Sin embargo, la figura 1 también muestra picos de elevación significativos entre 1998 y 2001, cuando las tasas se ubicaron entre 15 y 16 por cada 100000 habitantes, sobresaliendo como punto más bajo el año 1996 (tasa de 8,4), único año en el que la medida estuvo por debajo de 10 .

Seguidamente, en la tabla 2 se presentan los valores promedio de víctimas de homicidios culposos para diferentes periodos, registrándose los niveles más bajos en 2003 y los más altos en 2008. La tendencia al alza que pareciera venir gestándose en este tipo de muerte violenta y su vinculación con la accidentalidad vial, llevó precisamente en 2008, al inicio de una serie de reformas a la Ley de Tránsito, las cuales en tan pocos años han sufrido diversas modificaciones, en razón de su carácter draconiano y desproporcionado, por lo cual la Sala Constitucional ha acogido varias acciones de inconstitucionalidad en su contra. 
TABLA 2

PROMEDIO DE VÍCTIMAS DE HOMICIDIO CULPOSO POR AÑO, SEGÚN PERIODO

COSTA RICA, 2000-2009

(VALORES ABSOLUTOS)

\begin{tabular}{lccccc}
\hline \multirow{2}{*}{ AÑOS } & \multicolumn{5}{c}{ PROMEDIOS } \\
\cline { 2 - 5 } & DIARIO & SEMANAL & MENSUAL & TRIMESTRAL & SEMESTRAL \\
\hline 2000 & 1,64 & 11,58 & 50,17 & 150,50 & 301,0 \\
2001 & 1,71 & 11,98 & 51,92 & 155,75 & 311,5 \\
2002 & 1,58 & 11,20 & 48,17 & 144,50 & 289,0 \\
2003 & 1,45 & 10,15 & 44,00 & 132,00 & 264,0 \\
2004 & 1,52 & 10,73 & 46,50 & 139,50 & 179,0 \\
2005 & 1,51 & 10,62 & 46,00 & 138,00 & 276,0 \\
2006 & 1,65 & 11,56 & 50,08 & 150,25 & 300,5 \\
2007 & 1,69 & 11,86 & 51,42 & 154,25 & 308,5 \\
2008 & 1,76 & 12,36 & 53,58 & 160,75 & 321,5 \\
\hline 2009 & 1,62 & 11,40 & 49,42 & 148,25 & 296,5 \\
\hline
\end{tabular}

Fuente: Anuarios de Estadísticas Policiales del Poder Judicial, 2000-2009.

Por otra parte, la figura 2 evidencia el incremento en el promedio de víctimas al dividir la década estudiada en quinquenios, de manera que para el periodo 2005-2009 se produce un incremento en el valor absoluto para el caso del promedio general $y$ de hombres fallecidos.

FIGURA 2

PROMEDIO DE VÍCTIMAS FALLECIDAS EN HOMICIDIO CULPOSO POR SEXO, SEGÚN QUINQUENIO

COSTA RICA, 2000-2009

(VALORES ABSOLUTOS)

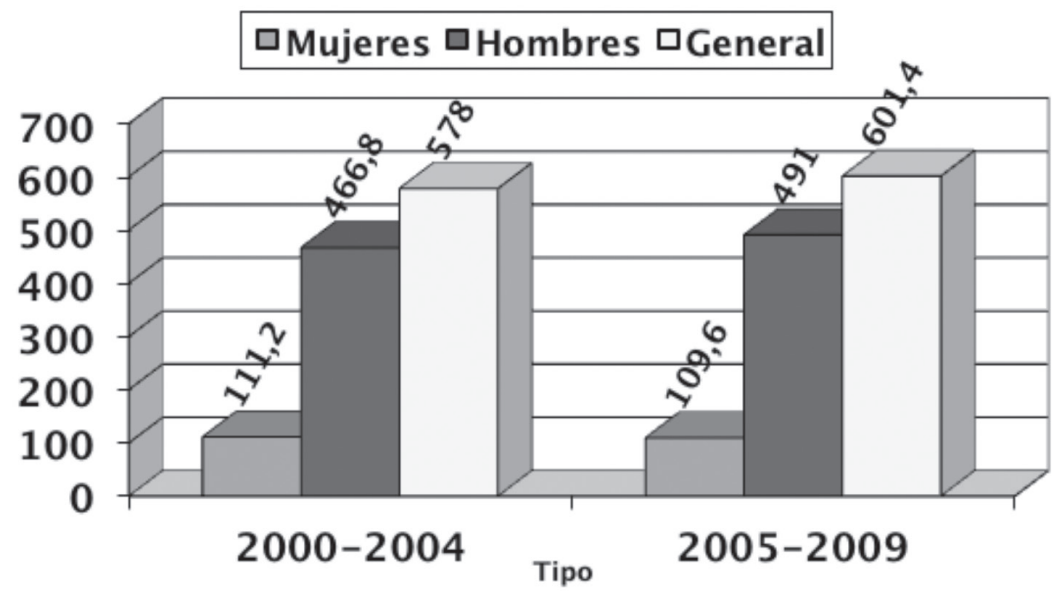

Fuente: Elaboración propia. 
En la figura 3 se muestra la tasa de homicidios culposos por quinquenios durante las dos últimas décadas (1990-1999/2000-2009), la cual expresa una tendencia al alza, pasando de 11,1 en el primer quinquenio a 13,9 en el último, donde el descenso observado entre el tercer y último quinquenio podría asociarse con la legislación promulgada en 2008.
Este aspecto ha llevado a algunos a respaldar el supuesto efecto preventivo de la sanción, defendiendo la imposición de altas multas $y$ tipificando como delitos, acciones de peligro abstracto como la conducción temeraria bajo efectos de bebidas alcohólicas. Lo anterior a pesar de que las campañas preventivas intimidatorias en el campo de la prevención en salud han demostrado su limitación en el tiempo.

FIGURA 3

COMPARACIÓN DE LA TASA DE HOMICIDIOS CULPOSOS POR 100000 HABITANTES SEGÚN QUINQUENIO

COSTA RICA, 1990-2009

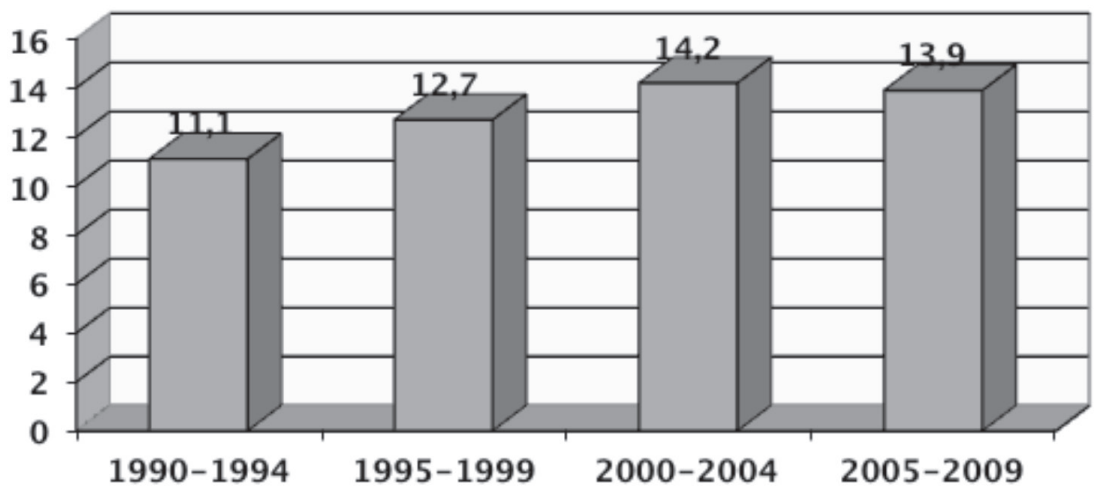

Fuente: Elaboración propia.

Por último, para finalizar este acápite, cabe visualizar las tasas de los diferentes tipos de muerte violenta (figura 4) a lo largo de la década en estudio. En la gráfica se puede apreciar una relativa estabilidad de la tasa de suicidios, mientras que la distancia en la tasa de homicidios culposos respecto a los dolosos tendió a disminuir hacia el final del periodo, específicamente a partir de 2007. No obstante, los homicidios culposos ocuparon a lo largo de la década ese protagónico primer lugar entre los motivos de muerte violenta en el país.

De esta manera, es más probable resultar muerto en la carretera por un conductor imprudente que a manos de un criminal que se oculta para robar, al estilo de la imagen de inseguridad ciudadana proyectada por los medios de comunicación (Sáenz, 2004).

Esto es así debido a que la conducción es una actividad lícita pero altamente riesgosa, de allí que esté regulada por una ley especial. Si además de riesgosa, las personas inobservan las normas dispuestas para realizarla (virar en "U", no hacer el "ALTO", obviar el "CEDA", entre otras), la tasa de muertes no tendría punto de comparación con la de homicidios dolosos ( $p$. Guido, comunicación personal, 12 de agosto de 2013). 
FIGURA 4

COMPARACIÓN DE LA TASA DE SUICIDIOS, HOMICIDIOS DOLOSOS Y CULPOSOS

POR CADA 100000 HABITANTES

COSTA RICA, 2000-2009

\section{- Suicidios Hom. Dolosos Hom. Culposos}

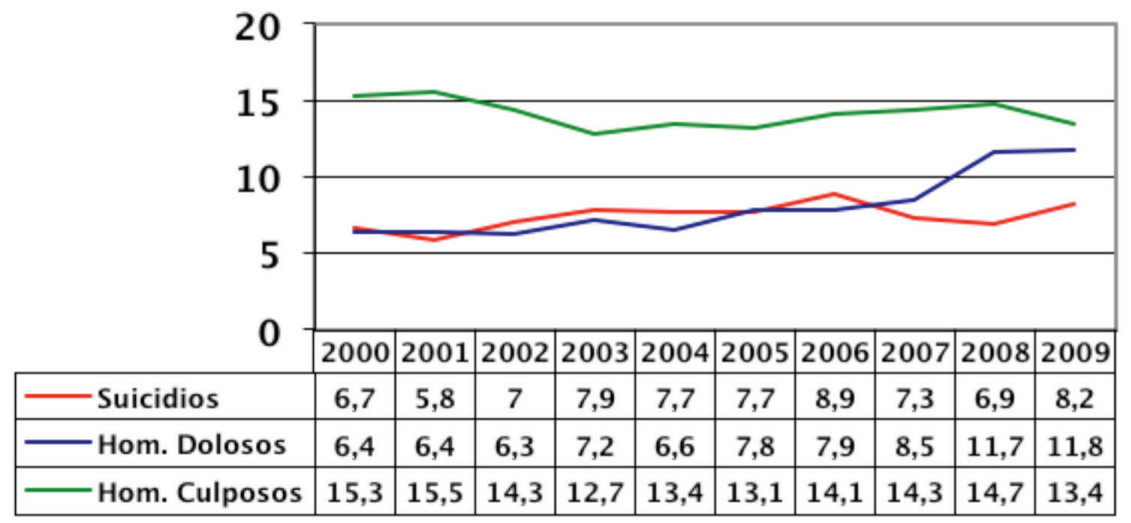

Fuente: Sáenz, 2010.

\section{ALGUNAS CARACTERÍSTICAS SOCIODEMOGRÁFICAS}

En lo referente a las características sociodemográficas de las víctimas, resalta que una mayoría abrumadora pertenece al sexo mas- culino (ver tabla 3 y figuras 5, 6 y 7), situación que vuelve a traer el tema de la asociación entre masculinidad y muerte violenta (Sáenz, 2010 y 2011), y cómo la socialización masculina expone a los niños desde temprana edad a presentar comportamientos agresivos $y$ temerarios.

TABLA 3

CARACTERÍSTICAS SOCIODEMOGRÁFICAS DE LAS VÍCTIMAS DE HOMICIDIO CULPOSO COSTA RICA, 2000-2009

(VALORES PORCENTUALES)

\begin{tabular}{lrrrrrrrrrr}
\hline VARIABLE/AÑO & 2000 & 2001 & 2001 & 2003 & 2004 & 2005 & 2006 & 2007 & 2008 & 2009 \\
\hline SEXO & & & & & & & & & & \\
Masculino & 80,6 & 82,2 & 80,4 & 80,5 & 79,9 & 82,2 & 78,4 & 79,7 & 83,2 & 84,7 \\
Femenino & 19,4 & 17,8 & 19,6 & 19,5 & 20,1 & 17,8 & 21,6 & 20,3 & 16,8 & 15,3 \\
\hline EDAD & & & & & & & & & & \\
Menos de 18 años & 13,9 & 14,0 & 9,9 & 12,3 & 13,4 & 15,0 & 12,3 & 11,5 & 9,0 & 9,3 \\
18 a 19 años & 3,3 & 3,7 & 1,9 & 5,5 & 2,9 & 3,3 & 3,3 & 5,8 & 5,9 & 5,0 \\
20 a 29 años & 23,0 & 22,8 & 18,2 & 18,9 & 22,6 & 18,3 & 21,7 & 22,9 & 23,3 & 23,4 \\
30 a 39 años & 15,8 & 17,2 & 17,0 & 16,5 & 15,0 & 15,0 & 13,8 & 14,6 & 18,2 & 17,4 \\
40 a 49 años & 15,6 & 14,0 & 19,0 & 6,5 & 16,5 & 13,6 & 16,3 & 15,2 & 13,7 & 14,3 \\
50 a 59 años & 10,0 & 11,1 & 13,5 & 11,6 & 10,6 & 14,3 & 12,5 & 10,5 & 12,9 & 13,0 \\
60 y más años & 18,4 & 17,3 & 0,6 & 18,7 & 19,0 & 20,5 & 20,1 & 19,5 & 17,0 & 17,5 \\
\hline
\end{tabular}


Continuación

\begin{tabular}{lrrrrrrrrrr}
\hline VARIABLE/AÑO & 2000 & 2001 & 2001 & 2003 & 2004 & 2005 & 2006 & 2007 & 2008 & 2009 \\
\hline PAÍ́S DE ORIGEN & & & & & & & & & & \\
Costa Rica & --- & 89,7 & 83,8 & 90,8 & 87,1 & 86,6 & 84,7 & 86,7 & 82,9 & 83,4 \\
Nicaragua & --- & 8,2 & 12,6 & 6,4 & 8,9 & 10,7 & 10,7 & 11,5 & 12,6 & 12,6 \\
Estados Unidos & --- & 0,5 & 0,7 & 0,8 & 0,4 & 1,2 & 1,2 & 0,2 & 0,4 & 0,8 \\
Otro centroamericano & --- & 1,0 & 0,7 & 0,6 & 1,6 & 0,5 & 1,5 & 0,2 & 1,2 & 1,2 \\
Sudamérica & --- & 0,3 & 0,4 & 0,4 & 0,2 & 0,2 & 1,3 & 0,8 & 0,9 & 0,2 \\
Europa & --- & --- & --- & 0,4 & 0,4 & 0,4 & 0,3 & 0,3 & 0,8 & 0,5 \\
Asia & --- & 0,3 & 0,4 & 0,4 & 0,2 & 0,2 & --- & --- & --- & 0,3 \\
Otro & --- & --- & 0,5 & 0,2 & --- & 0,2 & --- & --- & 0,2 & --- \\
Desconocido & --- & --- & 0,9 & --- & 1,2 & --- & 0,3 & 0,3 & 0,9 & 1,0 \\
\hline
\end{tabular}

Fuente: Anuarios de Estadísticas Policiales del Poder Judicial, 2000-2009.

Nota: --- No se registró información.

FIGURA 5

PROMEDIO DE VÍCTIMAS FALLECIDAS EN HOMICIDIO CULPOSO POR SEXO

COSTA RICA, 2000-2009

(VALORES PORCENTUALES)

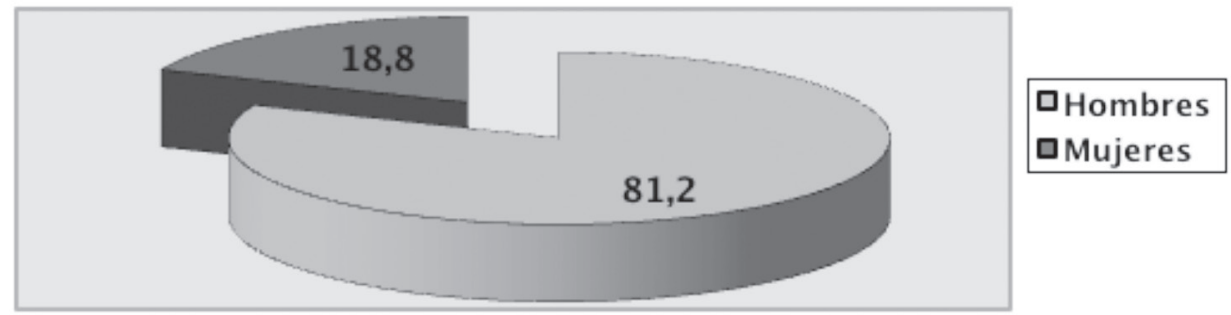

Fuente: Elaboración propia.

FIGURA 6

TASA DE VÍCTIMAS DE HOMICIDIO CULPOSO

POR CADA 100000 HABITANTE, POR SEXO

COSTA RICA, 2000-2009

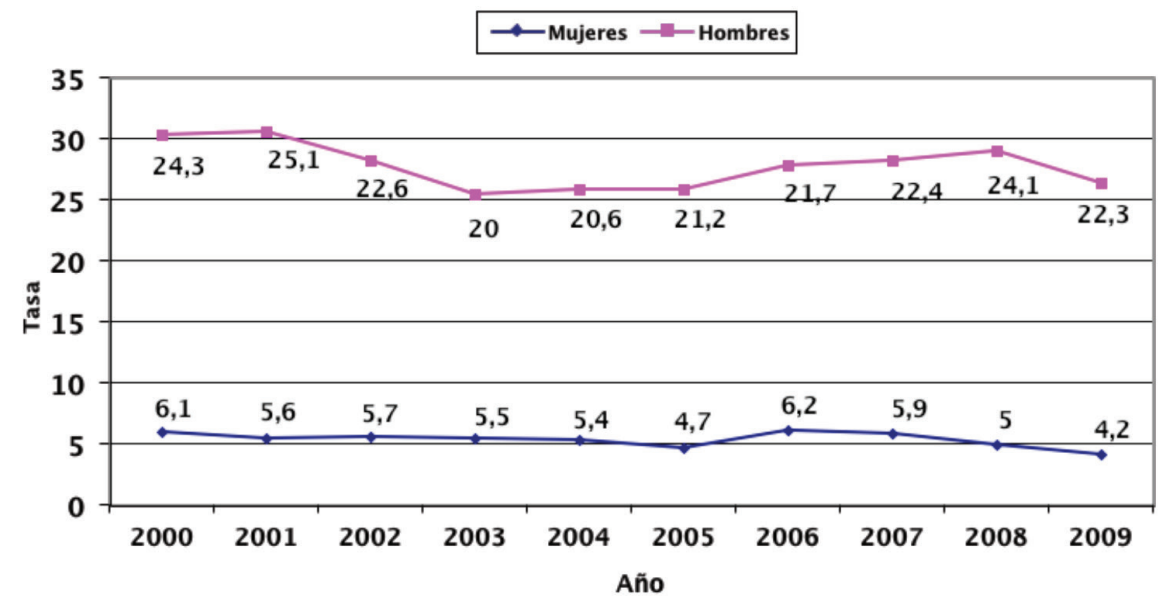

Fuente: Anuarios de Estadísticas Policiales del Poder Judicial, 2000-2009. 
En este sentido, la figura 7 destaca que la cantidad de hombres fallecidos por cada mujer, en las tres modalidades de muerte violenta, muestra una tendencia al alza hacia fines de la década, lo que podría implicar que la población masculina está más propensa a encontrarse en situaciones en que su vida corre peligro, gozando de menos mecanismos o estrategias para el afrontamiento de las mismas.

FIGURA 7

NÚMERO DE VÍCTIMAS MASCULINAS FALLECIDAS POR CADA MUJER POR HOMICIDIO DOLOSO, CULPOSO Y SUICIDIO

COSTA RICA, 2000-2009

(VALORES ABSOLUTOS)

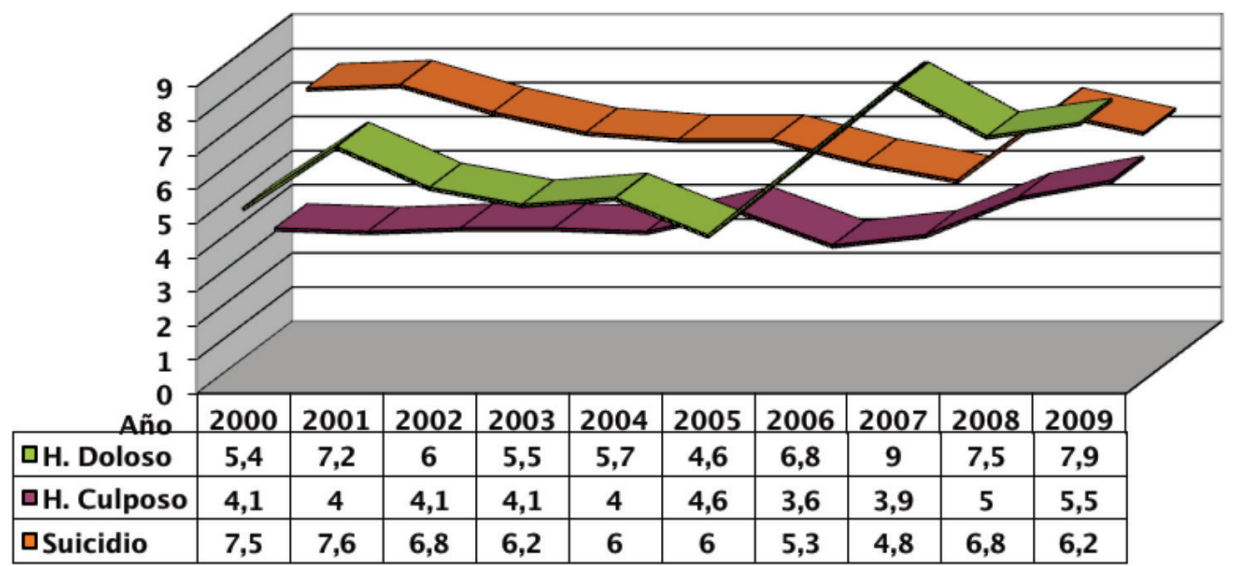

Fuente: Anuarios de Estadísticas Policiales del Poder Judicial, 2009-2009.

En cuanto al grupo etáreo, el sector poblacional joven vuelve a ser de riesgo en el tema de la muerte violenta, alcanzando en promedio más de la mitad de los casos en personas menores de 40 años de edad (ver figura 8), lo cual también se registró en el caso de los homicidios dolosos (Sáenz, 2010) y de los suicidios (Sáenz, 2011).

No obstante, llama la atención que en el caso de los homicidios dolosos, un $7,1 \%$ de las víctimas contaba con 60 años o más (Sáenz, 2010), mientras que en el caso de los suicidios fue de 10,4\% (Sáenz, 2011). Lo anterior pone en evidencia que este sector poblacional corre un mayor riesgo en el caso de los homicidios culposos, lo cual podría estar asociado con la paulatina disminución de funciones que experimentan, sobre todo en relación con su papel como conductores $y$ peatones. 
FIGURA 8

PROMEDIO DE VÍCTIMAS FALLECIDAS EN HOMICIDIO CULPOSO POR GRUPO ETÁREO

COSTA RICA, 2000-2009

(VALORES PORCENTUALES)

\section{Edad $\quad$ 口Menos de $20 \quad \square 20$ a $39 \quad \square 40$ a $59 \quad \square 60$ y más}

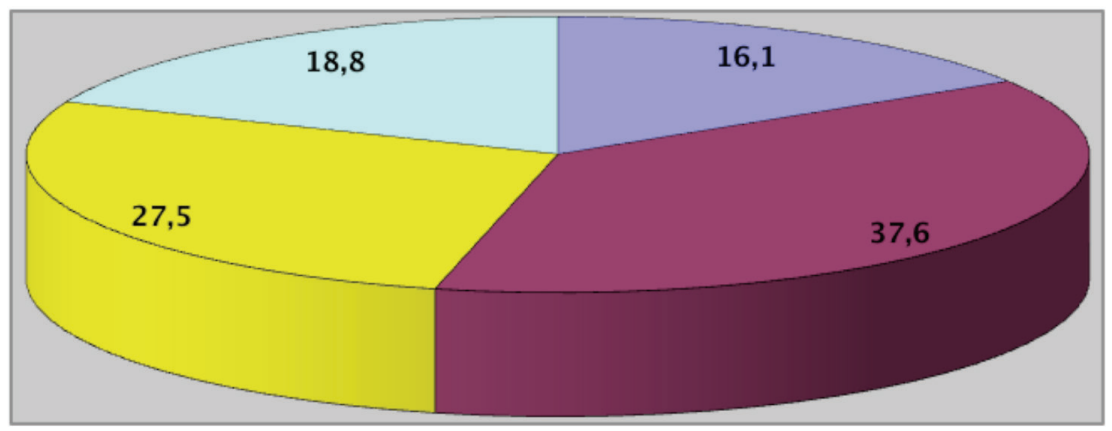

Fuente: Elaboración propia.

En lo relativo al país de origen de las personas fallecidas, sobresale la proporción de costarricenses, lo cual es naturalmente esperable, alcanzando un promedio para el periodo de $86,2 \%$, con una tendencia a disminuir hacia el final de la década. Cabe mencionar que en el caso de los homicidios dolosos, el promedio de costarricenses para la década fue del $77,8 \%$ (Sáenz, 2010), mientras que para los suicidios llegó al 87,7\% (Sáenz, 2011).

En el caso de las personas nicaragüenses, se presentó en el periodo un promedio de $10,5 \%$, contra un $15 \%$ en el caso de los homicidios dolosos (Sáenz, 2010) y un 12,3\% de extranjeros en casos de suicidio (Sáenz, 2011). Lo anterior pone en evidencia que es un grupo de riesgo en su condición de víctima de muertes violentas, puesto que las proporciones mostradas están por encima del porcentaje de nicaragüenses residentes en el país, según el último censo nacional, el cual se estableció en un 5,94\% (Instituto Nacional de Estadística y Censos, 2001).

\section{CONTEXTO ESPACIO-TEMPORAL}

En la tabla 4 y en la figura 9 se aprecian los porcentajes de víctimas de homicidios culposos por provincia, destacando que - como era esperable- San José y Alajuela obtuvieron los primeros lugares por tratarse de las provincias de mayor población a nivel nacional. 
TABLA 4

PERSONAS FALLECIDAS EN HOMICIDIO CULPOSO POR PROVINCIA DE OCURRENCIA DEL HECHO COSTA RICA, 2000-2009 (VALORES PORCENTUALES)

\begin{tabular}{lrrrrrrrrrr}
\hline PROVINCIA/AÑO & 2000 & 2001 & 2002 & 2003 & 2004 & 2005 & 2006 & 2007 & 2008 & 2009 \\
\hline San José & 28,7 & 27,1 & 30,0 & 24,1 & 25,6 & 22,6 & 27,9 & 26,9 & 26,6 & 24,0 \\
Alajuela & 19,8 & 18,8 & 19,0 & 21,2 & 21,7 & 16,7 & 13,5 & 17,3 & 18,9 & 25,5 \\
Cartago & 9,6 & 7,9 & 6,6 & 6,4 & 7,2 & 7,1 & 5,2 & 6,8 & 4,2 & 5,9 \\
\hline Heredia & 6,8 & 7,4 & 5,5 & 7,6 & 7,7 & 9,6 & 7,0 & 6,2 & 8,1 & 7,4 \\
Guanacaste & 9,6 & 13,2 & 21,2 & 11,2 & 9,7 & 10,1 & 13,1 & 13,6 & 13,4 & 9,4 \\
Puntarenas & 14,0 & 11,4 & 11,4 & 14,2 & 11,8 & 18,5 & 15,3 & 14,6 & 15,1 & 15,7 \\
Limón & 11,5 & 14,2 & 16,3 & 15,3 & 16,3 & 15,4 & 13,0 & 14,6 & 13,7 & 12,1 \\
\hline $\begin{array}{l}\text { TOTAL PERSONAS } \\
\text { (VALORES ABSOLUTOS) }\end{array}$ & 602 & 623 & 578 & 528 & 558 & 552 & 601 & 617 & 643 & 593 \\
\hline
\end{tabular}

Fuente: Anuarios de Estadísticas Policiales del Poder Judicial, 2000-2009.

No obstante, resulta interesante que Cartago y Heredia, siguientes en mayor población, registran los menores porcentajes de víctimas. Paralelamente, las restantes provincias, precisamente las provincias costeras y por ende, vacacionales, que además se encuentran entre las de mayor extensión territorial, más pobreza y menor densidad poblacional, sean las que registraron mayor proporción de víctimas después de San José y Alajuela, en su orden: Limón, Puntarenas y Guanacaste, superando de manera apreciable a Cartago y Heredia.

FIGURA 9

PROMEDIO DE PERSONAS FALLECIDAS EN HOMICIDIO CULPOSO

POR PROVINCIA, COSTA RICA 2000-2009

(VALORES PORCENTUALES)

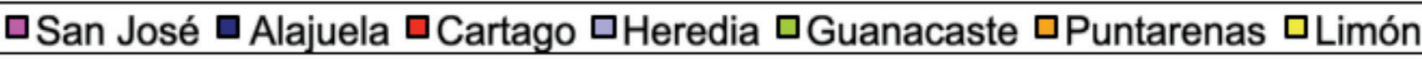

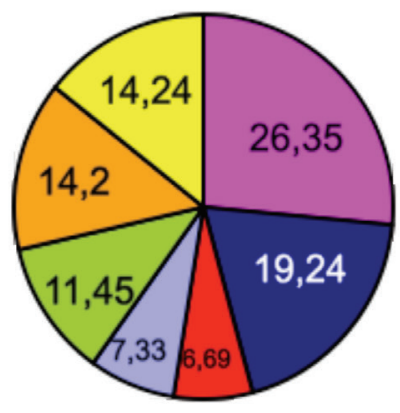

Fuente: Elaboración propia. 
En la tabla 5 y en la figura 10 se hace notorio que al relativizar las cifras y mostrarlas en tasas por 100000 habitantes, las provincias costeras, vacacionales, de mayor extensión territorial y con sectores de mayor pobreza, ocupan los primeros lugares referente a las víctimas. Esto podría asociarse con el tipo de carreteras y múltiples caminos vecinales, la carencia de alumbrado público en diversos trechos, lo cual facilitaría el aumento de velocidad en carreteras rectas o con poco tránsito, así como, dificultaría la visibilidad ante la falta de iluminación.

En Guanacaste, sobresale la carretera Interamericana Norte, desde el Río Lagarto hasta la frontera de Peñas Blancas; la carretera que va desde la Península de Nicoya hasta Liberia y la que va de Upala a Cañas; estas carreteras se caracterizan por la existencia de prolongadas rectas y tránsito relativamente escaso, el cual puede dar una sensación de seguridad en las curvas. Por su parte, con condiciones similares, Limón cuenta con la carretera Braulio Carrillo, desde el Río Sucio hasta la frontera de Sixaola y por último, Puntarenas con la Interamericana Norte, desde Esparza hasta el Río Lagarto; la Costanera Sur, desde el Río Grande de Térraba hasta Palmar Norte y la Interamericana Sur, desde el Río Cajón hasta la frontera de Paso Canoas.

TABLA 5

TASA POR 100000 HABITANTES DE VÍCTIMAS DE HOMICIDIO CULPOSO POR PROVINCIA, COSTA RICA, 2000-2009

\begin{tabular}{lrrrrrrrrrr}
\hline PROVINCIA/AÑO & 2000 & 2001 & 2002 & 2003 & 2004 & 2005 & 2006 & 2007 & 2008 & 2009 \\
\hline San José & 12,5 & 12,1 & 12,1 & 8,8 & 9,8 & 8,4 & 11,2 & 10,9 & 11,2 & 9,2 \\
Alajuela & 16,1 & 15,7 & 14,4 & 14,5 & 15,4 & 12,0 & 13,8 & 13,1 & 14,8 & 18,0 \\
Cartago & 13,0 & 10,9 & 8,3 & 7,3 & 8,5 & 8,0 & 6,4 & 8,6 & 5,5 & 7,0 \\
Heredia & 11,2 & 12,5 & 8,5 & 10,5 & 11,1 & 14,0 & 10,6 & 9,5 & 12,8 & 10,7 \\
Guanacaste & 21,3 & 20,9 & 23,2 & 20,7 & 18,7 & 19,0 & 26,7 & 27,9 & 28,1 & 18,0 \\
Puntarenas & 22,8 & 19,0 & 17,3 & 19,4 & 16,8 & 26,0 & 22,7 & 21,9 & 23,2 & 21,9 \\
Limón & 19,7 & 25,1 & 25,9 & 21,9 & 24,2 & 22,0 & 20,1 & 22,7 & 21,9 & 17,6 \\
\hline TOTAL & 15,3 & 15,5 & 14,3 & 12,7 & 13,1 & 13,1 & 14,1 & 14,3 & 14,7 & 13,4 \\
\hline
\end{tabular}

Fuente: Anuarios de Estadísticas Policiales del Poder Judicial, 2000-2009.

La figura 10 evidencia las cifras relativas promedio de muerte violenta en Costa Rica durante la década, donde destaca la provincia de Guanacaste con tasas más altas para el caso de homicidios culposos y suicidios, mientras que la provincia de Limón lo es para el caso de los homicidios dolosos y al mismo tiempo, obtiene un segundo lugar en los suicidios y los homicidios culposos. 
FIGURA 10

TASA PROMEDIO POR 100000 HABITANTES

POR TIPO DE VÍCTIMAS DE HOMICIDIO DOLOSO, CULPOSO Y SUICIDIO

SEGÚN PROVINCIA, COSTA RICA, 2000-2009

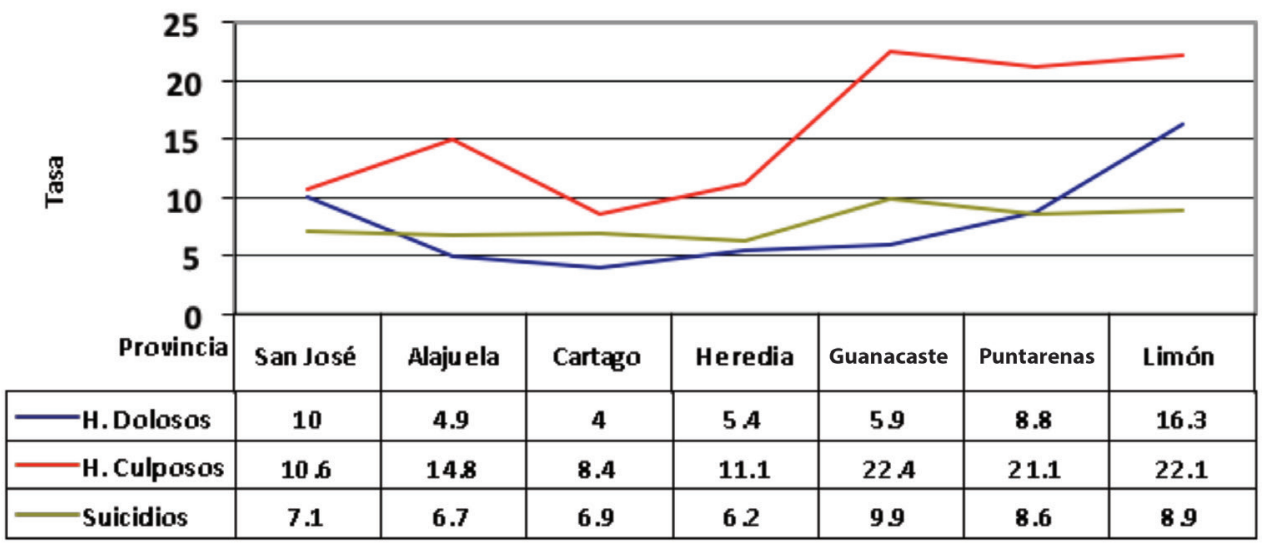

Fuente: Elaboración propia.

En concordancia con lo acontecido en las provincias, las regiones en las que el Ministerio de Planificación Nacional y Política Económica ha dividido el país, muestran un comportamiento similar. Específicamente, la Pacífico
Central, la Huetar Atlántica y la Chorotega registran tasas promedio muy superiores a la tasa promedio nacional, mientras que la Huetar Norte y la Brunca presentan ligeras elevaciones sobre 14 por cada 100000 habitantes.

TABLA 6

TASA DE PERSONAS FALLECIDAS POR HOMICIDIO CULPOSO

SEGÚN REGIÓN DE PLANIFICACIÓN

COSTA RICA, 2000-2009

\begin{tabular}{lrrrrrrrrrr}
\hline REGIÓN/AÑO & 2000 & 2001 & 2002 & 2003 & 2004 & 2005 & 2006 & 2007 & 2008 & 2009 \\
\hline Central & --- & 12,7 & 8,6 & 10,0 & 8,6 & 8,0 & 7,0 & 9,4 & 7,8 & 10,5 \\
Chorotega & --- & 12,0 & 10,9 & 8,9 & 9,5 & 9,1 & 8,0 & 8,4 & 8,4 & 7,1 \\
Pacífico Central & --- & 9,0 & 8,6 & 10,2 & 7,2 & 7,8 & 7,0 & 9,7 & 9,2 & 7,9 \\
Brunca & --- & 8,3 & 12,2 & 10,0 & 9,8 & 9,6 & 8,6 & 10,9 & 8,8 & 7,2 \\
Huetar Atlántica & --- & 6,1 & 7,8 & 8,5 & 7,9 & 6,9 & 6,3 & 8,6 & 7,3 & 8,3 \\
Huetar Norte & --- & 7,4 & 5,7 & 5,5 & 7,0 & 8,7 & 6,8 & 6,8 & 9,2 & 9,4 \\
\hline $\begin{array}{l}\text { TOTAL PERSONAS } \\
\text { (VALORES ABSOLUTOS) }\end{array}$ & 602 & 623 & 578 & 528 & 558 & 552 & 601 & 617 & 643 & 593 \\
\hline
\end{tabular}

Fuente: Anuarios de Estadísticas Policiales del Poder Judicial, 2000-2009.

Nota: --- No se registró información. 
FIGURA 11

TASA PROMEDIO DE PERSONAS FALLECIDAS POR HOMICIDIO CULPOSO SEGÚN REGIÓN DE PLANIFICACIÓN COSTA RICA, 2001-2009

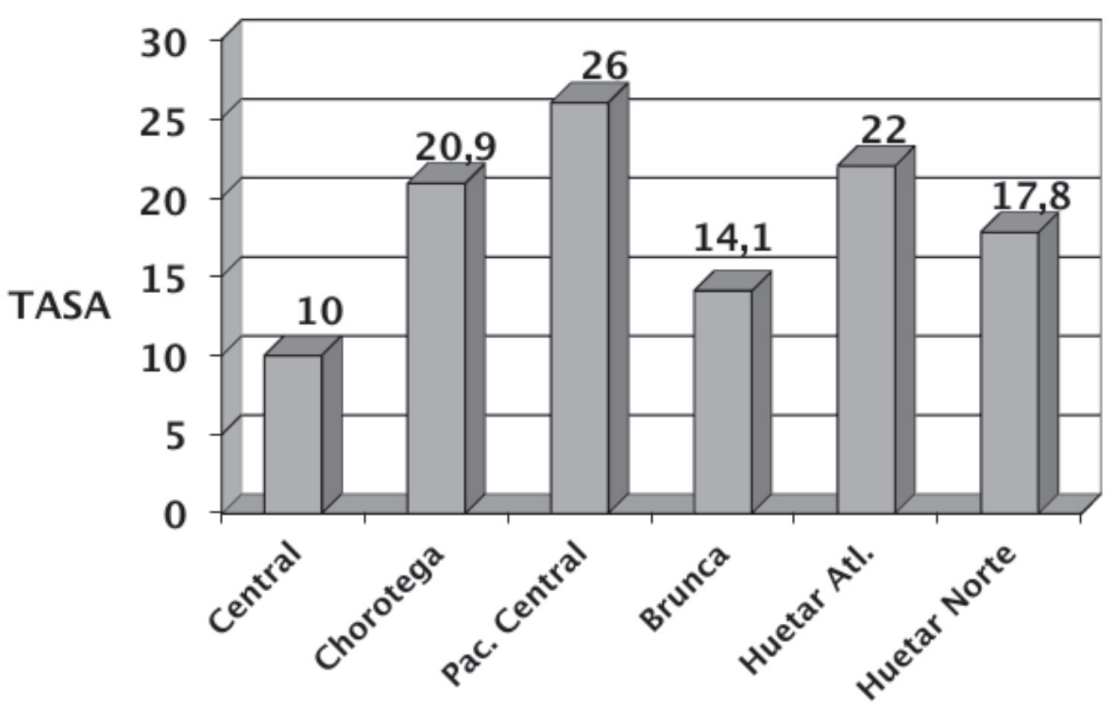

Fuente: Elaboración propia.

En la tabla 7, así como en las figuras 12 y 13 , se puede apreciar la distribución de personas fallecidas por homicidio culposo de acuerdo a los meses del año. Resalta que los meses que registran proporciones más altas son aquellos que componen la llamada "estación seca" (diciembre, enero, febrero, marzo y abril), además, en varios de ellos se disfruta de periodos vacacionales, lo cual podría asociarse con el hecho de que ante las favorables condiciones climáticas $y$ el ambiente festivo - con el consecuente consumo de bebidas alcohólicas - las personas tiendan a conducir con mayor imprudencia, a mayor velocidad $\mathrm{u}$ observando menores niveles de precaución. De hecho, en la figura 13 se muestra que el primer trimestre alcanza en promedio, la mayor proporción de víctimas por esta modalidad. Esta hipótesis cobra mayor valor explicativo si se analiza que las más altas tasas, se presentaron en las provincias costeras. 
TABLA 7

DISTRIBUCIÓN DE PERSONAS FALLECIDAS POR HOMICIDIO CULPOSO SEGÚN MES Y AÑO

COSTA RICA, 2000-2009

(VALORES PORCENTUALES)

\begin{tabular}{lrrrrrrrrrr}
\hline MES/AÑO & 2000 & 2001 & 2002 & 2003 & 2004 & 2005 & 2006 & 2007 & 2008 & 2009 \\
\hline Enero & 11,0 & 12,7 & 8,6 & 10,0 & 8,6 & 8,0 & 7,0 & 9,4 & 7,8 & 10,5 \\
Febrero & 9,5 & 12,0 & 10,9 & 8,9 & 9,5 & 9,1 & 8,0 & 8,4 & 8,4 & 7,1 \\
Marzo & 8,8 & 9,0 & 8,6 & 10,2 & 7,2 & 7,8 & 7,0 & 9,7 & 9,2 & 7,9 \\
Abril & 7,5 & 8,3 & 12,2 & 10,0 & 9,8 & 9,6 & 8,6 & 10,9 & 8,8 & 7,2 \\
Mayo & 6,2 & 6,1 & 7,8 & 8,5 & 7,9 & 6,9 & 6,3 & 8,6 & 7,3 & 8,3 \\
Junio & 8,8 & 7,4 & 5,7 & 5,5 & 7,0 & 8,7 & 6,8 & 6,8 & 9,2 & 9,4 \\
Julio & 7,8 & 6,6 & 6,2 & 7,4 & 8,8 & 9,4 & 9,8 & 7,9 & 8,4 & 7,8 \\
Agosto & 7,3 & 5,8 & 5,4 & 7,2 & 6,8 & 8,1 & 6,8 & 7,2 & 7,8 & 6,2 \\
Setiembre & 7,5 & 8,5 & 7,8 & 5,9 & 6,6 & 8,1 & 8,0 & 6,8 & 9,0 & 9,1 \\
\hline Octubre & 9,0 & 5,8 & 8,8 & 6,6 & 6,8 & 8,0 & 10,0 & 7,9 & 7,1 & 7,2 \\
Noviembre & 8,3 & 5,9 & 6,9 & 9,1 & 9,7 & 8,0 & 9,4 & 7,3 & 8,6 & 8,4 \\
Diciembre & 8,3 & 11,9 & 11,1 & 10,6 & 11,3 & 8,3 & 12,3 & 9,1 & 8,4 & 10,9 \\
\hline TOTAL PERSONAS & 602 & 623 & 578 & 528 & 558 & 552 & 601 & 617 & 643 & 593 \\
(VALORES ABSOLUTOS) & & & & & & & & & \\
\hline
\end{tabular}

Fuente: Anuarios de Estadísticas Policiales del Poder Judicial, 2000-2009.

Por el contrario, los meses asociados con la "estación lluviosa" presentan menor proporción de estas muertes, situación que podría reflejar que ante las carreteras mojadas y condiciones de menor visibilidad, los conductores se vuelven más cuidadosos y cautos a la hora de tomar el volante.

FIGURA 12

PROMEDIO DE PERSONAS FALLECIDAS EN HOMICIDIO CULPOSO POR MES, COSTA RICA, 2000-2009

(VALORES PORCENTUALES)
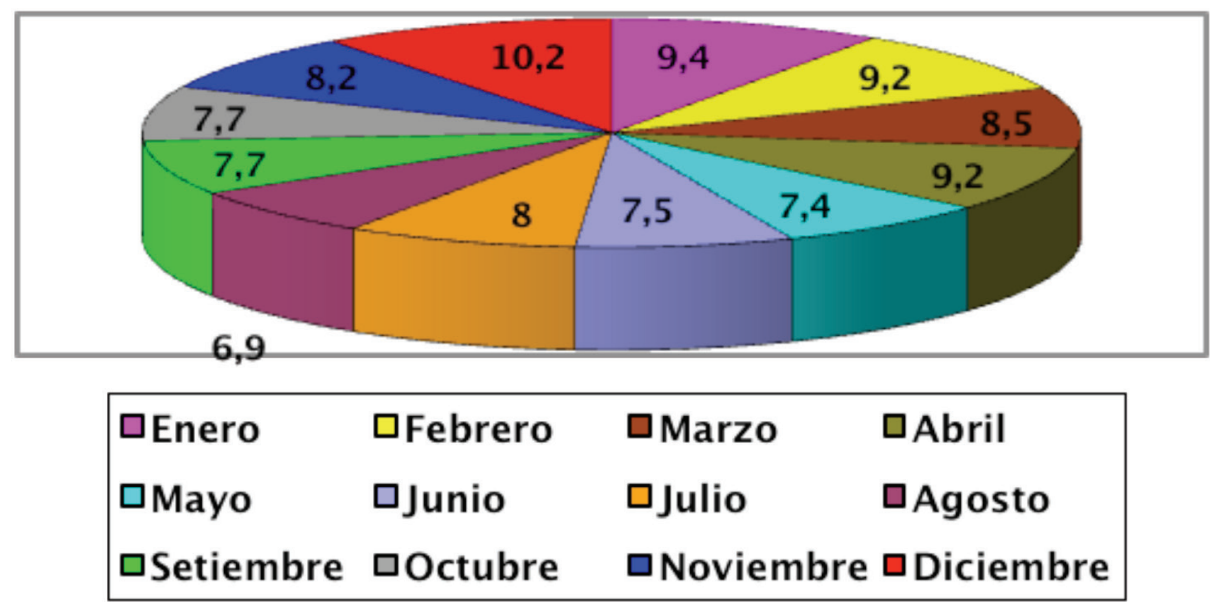

Fuente: Elaboración propia. 
FIGURA 13

PROMEDIO DE PERSONAS FALLECIDAS EN HOMICIDIO CULPOSO

POR TRIMESTRE, COSTA RICA 2000-2009

(VALORES PORCENTUALES)

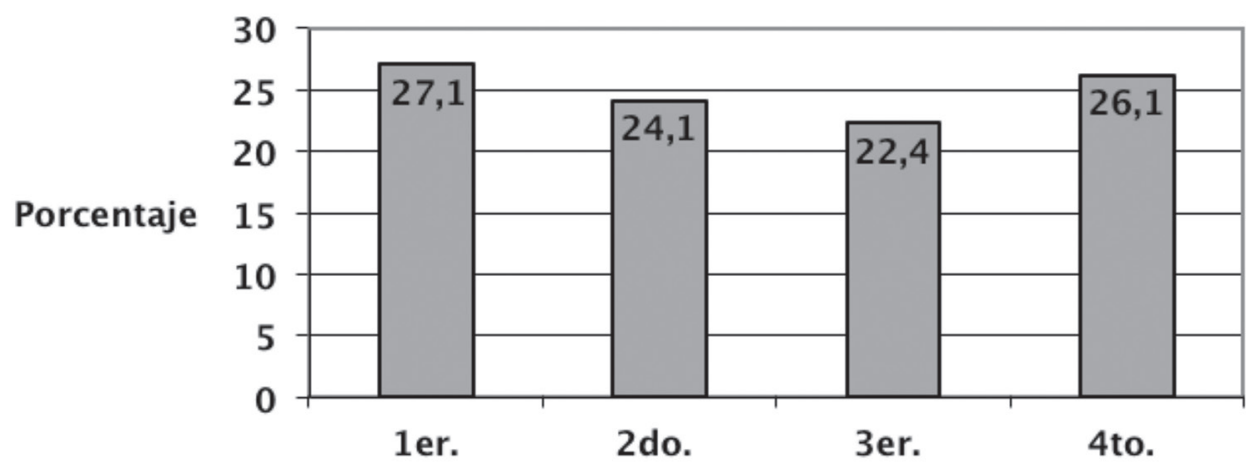

Trimestre

Fuente: Elaboración propia.

Tal como se aprecia en la tabla 8, en ocho de los diez años, el día domingo fue el que mayor proporción de víctimas produjo (a excepción de 2000 y 2008), lo cual se refleja en que obtuviera el mayor porcentaje promedio para la década (figura 14). Además, en esta misma tabla $y$ en las figuras 14 y 15, la proporción de víctimas cuyo fallecimiento ocurrió entre la semana (lunes, martes, miércoles y jueves) es bastante similar a la correspondiente a fines de semana (viernes, sábado $y$ domingo), aunque con una ligera ventaja para la primera categoría. No obstante, entre la semana se presentó un promedio diario de $12,85 \%$, mientras que en los fines de semana dicho promedio se estableció en un 16,20\%.

TABLA 8

DISTRIBUCIÓN DE PERSONAS FALLECIDAS EN HOMICIDIO CULPOSO

POR DÍA DE LA SEMANA, COSTA RICA, 2000-2009

(VALORES PORCENTUALES)

\begin{tabular}{lrrrrrrrrrr}
\hline DÍA/AÑO & 2000 & 2001 & 2002 & 2003 & 2004 & 2005 & 2006 & 2007 & 2008 & 2009 \\
\hline Lunes & 19,1 & 16,2 & 15,2 & 12,3 & 14,0 & 13,6 & 15,5 & 13,4 & 13,1 & 12,3 \\
Martes & 13,5 & 12,5 & 11,6 & 12,1 & 12,0 & 11,9 & 11,1 & 10,2 & 13,5 & 15,4 \\
Miércoles & 11,1 & 13,3 & 12,3 & 11,8 & 11,6 & 12,9 & 10,6 & 13,0 & 10,6 & 10,3 \\
\hline Jueves & 12,5 & 12,4 & 11,6 & 12,7 & 13,1 & 12,7 & 11,8 & 13,4 & 12,9 & 14,3 \\
Viernes & 11,9 & 13,3 & 13,5 & 15,5 & 12,9 & 16,1 & 14,0 & 12,6 & 15,1 & 14,3 \\
Sábado & 13,5 & 14,8 & 16,6 & 17,2 & 16,5 & 15,2 & 16,5 & 17,7 & 18,3 & 15,5 \\
Domingo & 18,4 & 17,5 & 19,2 & 18,4 & 19,9 & 17,6 & 20,5 & 19,6 & 16,5 & 17,9 \\
TOTAL & 251 & 262 & 261 & 300 & 280 & 338 & 351 & 369 & 512 & 525 \\
\hline
\end{tabular}

Fuente: Anuarios de Estadísticas Policiales del Poder Judicial, 2000-2009. 
FIGURA 14

PROMEDIO DE PERSONAS FALLECIDAS EN HOMICIDIO CULPOSO POR DÍA DE LA SEMANA COSTA RICA, 2000-2009

(VALORES PORCENTUALES)

\begin{tabular}{|c|c|c|c|}
\hline $\begin{array}{l}\text { QLunes } \\
\text { QViernes }\end{array}$ & $\begin{array}{l}\square \text { Martes } \\
\square \text { Sábado }\end{array}$ & $\begin{array}{l}\text { Miércoles } \\
\text { पDominqo }\end{array}$ & es \\
\hline
\end{tabular}

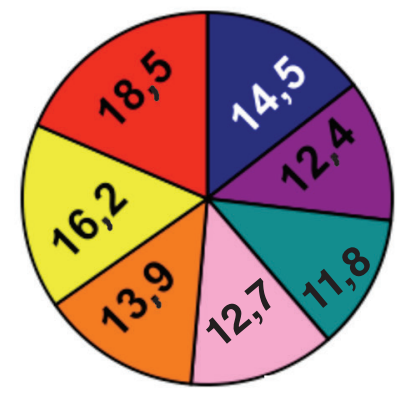

Fuente: Elaboración propia.

FIGURA 15

PROMEDIO DE PERSONAS FALLECIDAS EN HOMICIDIO CULPOSO POR ETAPA DE LA SEMANA COSTA RICA, 2000-2009

(VALORES PORCENTUALES)

\section{QEntre semana QFin de semana}

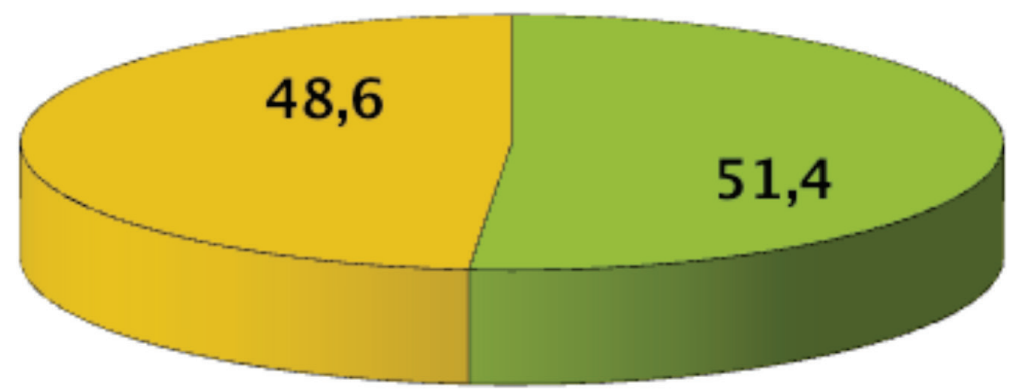

Fuente: Anuarios de Estadísticas Policiales del Poder Judicial, 2000-2009. 
FORMA DE MUERTE

En la tabla 9 es más que evidente que a lo largo de la década, las modalidades de atropello y colisión ocupan alternativamente, el primer $y$ segundo lugar, superando a las restantes categorías de manera significativa, lo cual se refleja en el promedio para el periodo (ver figura 16).

De esta manera, durante los 10 años en estudio, sistemáticamente más del $90 \%$ de las víctimas falleció en modalidades asociadas principalmente, con accidentes de tránsito (atropello, colisión, vuelco y precipitación), lo cual implica que una proporción importante de tales eventos, pudo haberse evitado si el comportamiento de los conductores se hubiese adecuado a la obligación del deber de cuidado; en efecto, los homicidios culposos se sancionan porque la acción u omisión llevó a un resultado previsible y evitable.

TABLA 9

DISTRIBUCIÓN DE PERSONAS FALLECIDAS EN HOMICIDIO CULPOSO POR LA MODALIDAD DEL HECHO COSTA RICA, 2000-2009

(VALORES PORCENTUALES)

\begin{tabular}{lrrrrrrrrrr}
\hline MODALIDAD/AÑO & 2000 & 2001 & 2002 & 2003 & 2004 & 2005 & 2006 & 2007 & 2008 & 2009 \\
\hline Atropello & 44,4 & 43,8 & 45,5 & 49,6 & 43,0 & 44,0 & 40,6 & 38,4 & 41,7 & 45,0 \\
Colisión & 45,8 & 44,0 & 39,3 & 39,2 & 46,4 & 43,3 & 47,4 & 46,4 & 46,2 & 45,9 \\
Mal praxis & 1,3 & 2,4 & 4,7 & 2,7 & 2,9 & 4,4 & 2,8 & 1,5 & 0,2 & 2,2 \\
Vuelco & 5,2 & 5,9 & 5,0 & 4,4 & 4,3 & 3,3 & 4,2 & 5,3 & 5,4 & 3,0 \\
Armas de fuego & 0,3 & 1,1 & 0,9 & 0,7 & 0,7 & 1,4 & 1,0 & 0,7 & 1,1 & 0,9 \\
Precipitación & 2,3 & 2,6 & 1,0 & 0,9 & 0,9 & 1,3 & 1,3 & 3,2 & 1,7 & 2,0 \\
Otras & 0,7 & 0,2 & 3,6 & 2,5 & 1,8 & 2,4 & 2,7 & 4,5 & 3,7 & 1,0 \\
\hline $\begin{array}{l}\text { TOTAL PERSONAS } \\
\text { (VALORES ABSOLUTOS) }\end{array}$ & 602 & 623 & 578 & 528 & 558 & 552 & 601 & 617 & 613 & 593 \\
\hline
\end{tabular}

Fuente: Anuarios de Estadísticas Policiales del Poder Judicial, 2000-2009.

FIGURA 16

PROMEDIO DE PERSONAS FALLECIDAS EN HOMICIDIO DOLOSO

SEGÚN EL MÉTODO O MODALIDAD UTILIZADA

COSTA RICA, 2000-2009

(VALORES PORCENTUALES)

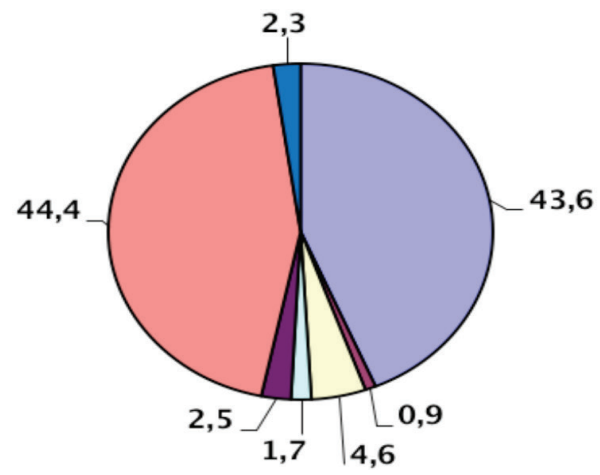

口Atropello $\square$ Arma de Fuego $\square$ Vuelco $\square$ Precipitación $\square$ Mal Praxis $\square$ Colisión $\square$ Otras

Fuente: Elaboración propia. 


\section{DISCUSIÓN}

Una vez analizados los datos, llama poderosamente la atención que a pesar de mostrar un leve descenso a lo largo de la década, los homicidios culposos continúan siendo la principal causa de muerte violenta en Costa Rica. El perfil de las víctimas indica que mayoritariamente, son personas jóvenes, hombres y costarricenses. Sin embargo, es importante que el Organismo de Investigación Judicial recopile más información de carácter sociodemográfico en torno a las víctimas, al igual que respecto al infractor, de manera que pueda servir para generar algún tipo de intervención preventiva. De particular interés para la generación de políticas de salud pública y prevención del delito, sería relevante en los casos de accidentes de tránsito, el registro de las alcoholemias positivas tanto de conductores como de peatones, al igual que de los imputados.

Además, vuelve a aparecer el vínculo entre masculinidad $y$ violencia como un eje central en el ámbito de la muerte violenta (Sáenz, 2010 y 2011). Esto lleva a insistir en la necesidad de revisar la educación con un enfoque de género, la cual permita desvincular estos dos elementos, de manera que construirse como hombre no requiera de ejercer comportamientos violentos, agresivos o temerarios.

A pesar que no se puede aseverar que todos los homicidios culposos sean producto de accidentes de tránsito, lo cierto es que una cifra abrumadora (más del 90\% en promedio para la década) sí ocurre en estas condiciones, razón por la cual merecen especial mención dichos accidentes. Aunado a ello, la condición de falta al deber de cuidado (expresada por la imprudencia, negligencia o impericia) que caracteriza estos homicidios, permite prever la ocurrencia de hechos con desenlaces fatales y por ende, evitarlos apegando los comportamientos relacionados con la conducción vehicular al deber ser o deber de cuidado.

Otro aspecto relevante es que precisamente en aquellas zonas del país donde se registran las más altas tasas de víctimas de homicidios culposos, ya sea por provincia o por región de planificación, se caracterizan por contar con largas carreteras, amplias rectas, relativamente poco tránsito vehicular y escasa vigilancia. De acuerdo con Moreno y Monge (2009 y 2011) estas variables son de gran relevancia, puesto que podrían ser disparadores del incremento de velocidad $y$ por ende, de la ocurrencia de accidentes de tránsito con resultados lamentables. Lo anterior cobra aún mayor importancia sí se toma en consideración que la mayoría de eventos ocurren en los meses de la estación seca, asociada con periodos vacacionales, al igual que se registró un mayor promedio diario en fines de semana, cuando las familias tienden a salir más de paseo.

Ahora bien, en el marco de una política criminal propia de un Estado social y democrático de Derecho, la prevención de los homicidios culposos no está necesariamente en la respuesta represiva del Gobierno, buscando la intimidación de la colectividad (Sáenz, en prensa). Por el contrario, se encuentra en la articulación de una serie de medidas en diversos frentes que de manera lógica y coherente se dirijan a minimizar la ocurrencia de estos hechos.

De esta manera, ante la innegable participación de los accidentes de tránsito en este tipo de mortalidad, como consecuencia más grave, y sin dejar de lado otras implicaciones, tales como, las lesiones culposas (algunas de ellas de carácter permanente), las secuelas emocionales para las víctimas y sus familiares, la pérdida de días laborales, las incapacidades médicas, las pérdidas materiales y los costos de seguros, entre otras. Cabe discutir algunas medidas que la investigación social sustenta y podrían tener un efecto preventivo.

En primera instancia, el hecho de que a menor edad mayor aumenta la intención de incrementar la velocidad $y$ mayor presencia de comportamientos de riesgo al conducir, aunado a que en promedio, a lo largo de la década, una cuarta parte de las víctimas contaba con una edad entre los 18 y los 30 años (25,57\%), sugiere la posibilidad de aumentar la edad legal para obtener la licencia de conducir, así como revisar los contenidos de la seguridad vial como eje transversal del currículum, insertándolo desde la educación preescolar, al igual que el examen teórico practicado por el Instituto Nacional 
de Aprendizaje, valorando la posibilidad de incluir pruebas en simulador, donde el aspirante a obtener la licencia deba superar diferentes problemas o situaciones disonantes que se le presenten durante la prueba.

En segundo lugar, en las provincias y regiones donde más homicidios culposos se registran en tasas por 100000 habitantes, caracterizadas por carreteras largas, con amplias rectas y escaso tránsito $y$ vigilancia, aspectos que se han asociado con la tendencia a incrementar la velocidad, se podrían ver disminuidos los accidentes si se instalan reductores de velocidad en carretera, si se colocan a la orilla avisos de proximidad de patrullas de vigilancia (cuyo rol sea preventivo y no represivo), así como, la instalación de una adecuada iluminación eléctrica. Lo anterior se puede complementar con iniciativas de mayor vigilancia los fines de semana $y$ en los meses de la estación seca, no con el ánimo de realizar multas, sino de disuadir a los conductores de cometer infracciones de tránsito.

En tercer lugar, la asociación entre algunas variables de personalidad (susceptibilidad al aburrimiento, desinhibición y búsqueda de experiencias) y la cantidad de infracciones, así como de accidentes (Moreno y Monge, 2009) permite plantear también un aspecto de suma relevancia en el que ha insistido el Colegio Profesional de Psicólogos y Psicólogas de Costa Rica, respecto a la necesidad de realizar pruebas de idoneidad mental a aquellas personas que desean obtener su licencia de conducir. No obstante, para evitar actos de corrupción, lo conveniente sería que las y los profesionales que realicen dichas evaluaciones psicológicas sean funcionarias(os) del Consejo de Seguridad Vial o bien, que dicho Colegio ejerza una función de supervisión estricta de manera que no se creen monopolios ni se permita a profesionales reportar una cantidad de evaluaciones que en términos humanos sería imposible realizar en el tiempo indicado.

En otro orden de cosas, resulta interesante que hay una serie de condiciones asociadas con la conducción vehicular que pareciera le brindan a los conductores, cierta sensación de seguridad y por ende, una auto-percepción sesgada (optimismo irreal o sesgo optimista) que facilita a las personas, la presencia de ideas irracionales en torno a que les ocurran eventos negativos ("a mí no me va a pasar" o "eso le ocurre a otros"), a pesar de presentar factores o comportamientos de riesgo. De esta manera convendría generar proyectos de investigación que profundicen en esta perspectiva, para lo cual se puede coordinar la aplicación de escalas, inventarios de personalidad, así como, grupos focales y entrevistas en profundidad.

Para finalizar, un aspecto que atañe específicamente a la dogmática y a la doctrina jurídico-penal, es la discusión de si efectivamente en las muertes ocurridas en todos los accidentes de tránsito media la culpa o en algunos casos, se podría aplicar el dolo eventual; sobre todo en aquellos en los que el conductor se encuentra bajo efectos de bebidas alcohólicas, puesto que, de acuerdo a las modificaciones realizadas en la Ley de Tránsito, el solo hecho de conducir bajo efectos de esta droga lícita es considerado un acto temerario tipificado como delito doloso de peligro abstracto ("contra la seguridad común").

\section{BIBLIOGRAFÍA}

Carranza, E. Criminalidad. ¿Prevención o promoción? San José: Universidad Estatal a Distancia, 1994.

Zúñiga, Ulises. Código Penal 23 edición. San José, Costa Rica: Investigaciones Jurídicas, 2009.

Féliz, L. E.; de la Cruz, M.; de los Santos, M. y Ramos, N. M. "Violencia y alcohol: un estudio comparativo de los niveles de alcohol en sangre en pacientes accidentados $y$ en víctimas de un intento de homicidio". Revista Científica Hogar CREA Dominicano 1 (2). 1992: 13-17.

Ganzenmüller, C.; Escudero, J. F. y Frigola, J. Homicidio y asesinato. Barcelona, España: Bosch, 1996.

Instituto Nacional de Estadística y Censos. IX Censo Nacional de Población y $\mathrm{V}$ de Vivienda: Resultados Generales. San José: INEC, 2001.

Matos, R.; Betancourt, A.; Álvarez, E.; Aces, S. y Toirac, S. "Muertes violentas y consumo 
de alcohol". Adicciones 13 (1). 2001: 75-80.

Moreno, M. y Monge, D. "Intención de aumento de velocidad y evaluación del riesgo según contextos viales". Revista de Ciencias Sociales 125. San José, Costa Rica. Editorial de la Universidad de Costa Rica, 2009: 127-139.

Moreno, M. y Monge, D. "Actitudes hacia comportamientos protectores $y$ de riesgo en conductores costarricenses". Revista Costarricense de Psicología 45-46. 2011: 35-49.

Poder Judicial de Costa Rica. Departamento de Planificación. Anuarios de Estadísticas Policiales. 1990-2010. En:<http://www. poder-judicial.go.cr/planificacion/ Estadisticas/policiales.html>.

Sáenz, M. A. "Hacia una nueva concepción de la prevención del delito". La violencia en Costa Rica en los albores del nuevo milenio. M. A. Sáenz y M. González (eds.). San José: Guayacán, en prensa.

Sáenz, M. A. "El papel de los medios de comunicación en la construcción social del fenómeno de la criminalidad". Cuadernos de Estudio del Ministerio Público de Costa Rica 8. 2004: 49-57.

Sáenz, M. A. "Magnitud, frecuencia y características sociodemográficas de los homicidios dolosos en Costa Rica". Revista Costarricense de Psicología 44. 2010: 1-17.

Sáenz, M. A. "Aportes para una epidemiología del suicidio en Costa Rica: un análisis de la primera década del siglo xxı". Revista de Ciencias Sociales 131-132. San José, Costa Rica. Editorial de la Universidad de Costa Rica, 2011: 37-55.

Sproviero, J. H. Delitos de homicidio. Buenos Aires, Argentina: Rocca, 1996.

Zaffaroni, E. R.; Alagia, A. y Slokar, A. Derecho penal: parte general. 2nda. edición. Buenos Aires, Argentina: EDIAR, 2003.

Fecha de ingreso: 14/08/2013 Fecha de aprobación: 16/09/2013 
